\title{
Numbats and aardwolves - how low is low? A re-affirmation of the need for statistical rigour in evaluating regression predictions.
}

\author{
Cooper, C.E ${ }^{*}$ and Withers, P.C.
}

*Corresponding author

Department of Environmental Biology, Curtin University of Technology, PO Box U1987

Perth Western Australia

Zoology, School of Animal Biology M092, University of Western Australia, Crawley

Western Australia 6009

Contact details:

Dr Christine Cooper

Department of Environmental Biology

Curtin University of Technology

PO Box U1987

Perth, Western Australia

$\mathrm{Ph}+61892667965$

Fax +61 892662495

e-mail C.Cooper@curtin.edu.au

Dr Philip Withers

Zoology, School of Animal Biology M092

University of Western Australia

Crawley, Western Australia 6009

$\mathrm{Ph}+61864882235$

Fax +61864881029

e-mail pwithers@cyllene.uwa.edu.au 


\begin{abstract}
Many comparative physiological studies aim to determine if a particular species differs from a prediction based on a linear allometric regression for other species. However, the judgment as to whether the species in question conforms to this allometric relationship is often not based on any formal statistical analysis. An appropriate statistical method is to compare the new species' value with the $95 \%$ confidence limits for predicting an additional datum from the relationship for the other species. We examine the basal metabolic rate of the termitivorous numbat (Myrmecobius fasciatus) and aardwolf (Proteles cristatus) to demonstrate the use of the $95 \%$ prediction limits to determine statistically if they have a lower-than-expected BMR compared to related species. The numbat's BMR was $83.6 \%$ of expected from mass, but fell inside the $95 \%$ prediction limits for a further datum; a BMR $<72.5 \%$ of predicted was required to fall below the 1tail $95 \%$ prediction limits. The aardwolf had a BMR that was only $74.2 \%$ of predicted from the allometric equation, but it also fell well within the $95 \%$ prediction limits; a BMR of only $41.8 \%$ of predicted was necessary to fall below the 1-tail $95 \%$ prediction limits. We conclude that although it is difficult to demonstrate that a single species statistically differs from a regression relationship for other species, the use of a formal statistical approach is essential.
\end{abstract}

\title{
Abbreviations and Symbols
}

BMR basal metabolic rate

C thermal conductance

EWL evaporative water loss

FMR field metabolic rate

$\dagger \quad$ mean $X$

$\hat{Y} \quad$ predicted $\mathrm{Y}$ value

$\Sigma \mathrm{X}^{2} \quad$ corrected sum of squares for $\mathrm{X}$

SY.X standard error of estimate for $\mathrm{Y}$

SŶ $\quad$ standard error of predicted $\mathrm{Y}$

Keywords prediction limits, regression, numbat, aardwolf, termitivore. 


\section{Introduction}

It is frequently of interest in comparative or allometric physiological studies to determine if a particular species, with a distinctive suite of life history and ecological characteristics, differs from an allometric prediction based on other species. Body mass has a major allometric effect on most physiological variables including BMR (Kleiber 1932; Aschoff and Pohl 1970; Hassen and Lacy 1985; McNab 1988; Reynolds and Lee 1996; Withers et al. 2000; White and Seymour 2003; Withers et al. in press), C (Bradley and Deavers 1980; Aschoff 1981; Withers et al. 2000; Schleucher \& Withers 2001; Withers et al. in press), FMR (Nagy 1987, 1994; Cooper and Withers 2003), and EWL (Crawford and Lasiewski 1968; Hinds and MacMillen 1985, 1986; Williams 1996, Withers et al. in press). To compare the measured value of a physiological variable for a particular species with that predicted from other species, we must first determine the allometric relationship of that variable for the other species then assess whether the species in question conforms to this relationship.

Standard least squares regression is typically used in comparative studies of a number of species to determine the linear relationship between body mass and a physiological variable e.g. $\mathrm{Y}=\mathrm{a}+\mathrm{b} . \mathrm{X}$, where $\mathrm{X}$ is $\log _{10}$ body mass and $\mathrm{Y}$ is the physiological variable in question (usually $\log _{10}$ transformed). Regression indicates the statistical significance of the relationship $\left(\mathrm{F}\right.$ test or $\mathrm{R}^{2}$ ), and provides variance estimates for both the intercept (a) and the slope (b). Regression also has predictive statistical uses. For example, the $95 \%$ confidence band for the regression is often calculated and shown graphically, to indicate the goodness of fit i.e. how 'tightly' the data points fit the linear regression line. 
Once an allometric relationship has been established, it is possible to determine whether a new species conforms to this relationship. Unfortunately, this judgment is often not based on any statistical analysis. We compiled a list of recent (between 2000 and 2005) papers that assess variation from regression relationships by searching Biological Abstracts for studies of physiological variables commonly analysed by regression (e.g BMR, RMR, MMR, FMR, EWL). For studies for which regression analysis was carried out, the method of predicting a species' position on the allometric line was examined. Those papers for which the methods were clear are those listed. No correctly statistically analysed papers were found during this search, but the following 23 recent studies are examples of a common approach whereby a physiological variable for a species (e.g. BMR, C, EWL etc) is subjectively judged to be different from the allometrically expected value (Baudinette et al. 2000, Geiser and Brigham 2000, McNab 2000, Merola-Swartjes and Ligon 2000, Weathers et al. 2000, Anava et al. 2001, McNab 2001, Williams 2001, Williams et al. 2001, Klaassen et al. 2002, Schleucher 2002, Bonaccorso and McNab 2003, Burton and Weathers 2003, Cortes et al. 2003, Kalin et al. 2003, Lindstrom and Klaassen 2003, Lovegrove and Smith 2003, McKechnie and Lovegrove 2003, Peinke and Brown 2003, Song and Wang 2003, Bozinovic et al. 2004, Mathias et al. 2004, Williams et al. 2004). The percentage of the species' value relative to the expected value (obtained from the allometric equation for an animal of equivalent mass) was interpreted to be high (somewhat greater than 100\%), low (somewhat less than 100\%) or as expected (around $100 \%)$. However this subjective approach lacks statistical rigor. It is not clear how much lower a species has to be than the expected value to be considered low, or how much higher does it has to be, or in what range a value should be considered to be as expected. 
Rather, formal statistical methods should be used to determine if a species' trait is significantly lower or higher than expected (Garland and Adolph 1994; Nagy et al. 1999;

$\begin{array}{lll}\text { Garland } \text { and 2000). } & \text { Ives }\end{array}$

We use a standard statistical method for obtaining the $95 \%$ prediction confidence limits for a regression to compare the new species' value as an additional datum for the linear regression relationship for other species (e.g. Zar 1999; see Methods).

Here we investigate the BMR of two phylogenetically distinct termitivorous mammals, the marsupial numbat (Myrmecobius fasciatus) and the placental aardwolf (Proteles cristatus). We use the 95\% prediction confidence limits for the BMR of related non-termitivorous species to determine statistically if these termitivorous species have a lower-than-expected BMR, both before and after phylogenetic correction. According to McNab (1984, 2000), mammals of $>200$ g body mass that feed extensively on termites have a BMR lower than predicted from body mass, presumably reducing their overall energy expenditure because a termite diet is considered to have a low net energy yield (Redford and Dorea 1984, McNab 1984, Abensperg-Traun et al. 1991). However, McNab's analysis was conducted without rigorous statistical testing, just comparing BMRs predicted from allometric equations with the measured value and subjectively deciding if the measured value was lower than the expected value. His analysis was also conducted prior to the widespread introduction of phylogenetically independent comparative methods.

Numbats are small-to-medium sized $(550 \mathrm{~g})$ marsupials, in the monospecific family Myrmecobiidae. Morphological features and serological and albumin systematics indicate that the numbat is most closely related the marsupial family Dasyuridae, forming 
(with the extinct Thylacinidae) the superfamily Dasyuroidea (Kirsch 1968, Archer and Kirsch 1977, Archer 1984, Baverstock et al. 1990), so we compare the numbat with the other Dasyuroidea (dasyurids). Aardwolves belong to the family Hyaenidae, and are thought to have a civet-like viverrid ancestor (Anderson et al. 1992), so we compare the aardwolf with Carnivora. The numbat and the aardwolf are ideal species to examine the possible influence of a termitivorous diet on BMR as both are the only strictly termitivorous members of their carnivorous lineages. Therefore comparison of their BMR with those of their nearest relatives (numbats with dasyurids and aardwolves with other carnivores) may indicate a dietary effect on BMR. In this way, potential physiological adaptation to their specialised diet can be separated from phylogenetic influence that may confound the interpretation of comparative analysis. Such a direct comparison is not possible for other myrmecophagous mammals (such as anteaters and pangolins) as there is no direct comparison with closely related non-myrmecophagous species.

\section{Methods}

BMR for numbats (550 g, $215.3 \mathrm{ml} \mathrm{O}_{2} \mathrm{~h}^{-1}$; Cooper and Withers 2002) and aardwolves (7950 g, $2019 \mathrm{ml} \mathrm{O}_{2} \mathrm{~h}^{-1}$; Andersen et al. 1997) was compared to other species of the superfamily Dasyuroidea ( $\mathrm{n}=18$, Withers et al. in press) and order Carnivora $(\mathrm{n}=30$, Lovegrove 2000) respectively. Standard least squares regression was used to determine the relationship between log-transformed mass and BMR for dasyurids and carnivores (excluding the numbat and aardwolf respectively) and 95\% prediction confidence limits were calculated for each dataset as outlined below (after Zar 1999). Autocorrelation (Cheverud and Dow 1985) was used to account for phylogenetic history, providing 
phylogenetically-corrected $\log _{10}$ mass and $\log _{10} \mathrm{BMR}$ residuals that were also used in an allometric regression, and for which $95 \%$ prediction limits were also calculated. A phylogenetic tree was constructed for the Dasyuroidea after Kirsch et al. (1997) and Kirsch and Palma (1995), and for the Carnivora after Bininda-Emonds et al. (1999).

The standard statistical procedure for predicting a single new $\mathrm{Y}$ value at a particular $\mathrm{X}$ value first determines the regression relationship $\mathrm{A}+\mathrm{Bx}$ for the data points excluding the X,Y values for the particular species in question (see Zar 1999). The predicted value of $Y$ for a new species $\left(\hat{Y}_{n s}\right)$ at a specified $X_{n s}$, is simply $\hat{Y}_{n s}=A+b \cdot X_{n s}$. The $95 \%$ prediction confidence limits of $\hat{\mathrm{Y}}_{\mathrm{ns}}$ were calculated as

$$
\hat{\mathrm{Y}}_{\mathrm{ns}} \pm \mathrm{t}_{\alpha(2),(\mathrm{n}-2)} \mathrm{S} \hat{\mathrm{Y}}
$$

where $\alpha$ is the probability value (0.05) for a two-tail test and $S_{\hat{Y}}$ is the standard error of the predicted $\hat{\mathrm{Y}}$ value, calculated from the regression residual mean square ( $\left.\mathrm{s}_{\mathrm{Y} . \mathrm{X}}\right)$ i.e.

$$
\mathrm{S}_{\hat{Y}}=\mathrm{S}_{\mathrm{Y} . \mathrm{X}} \sqrt{ }\left[1+(1 / \mathrm{n})+\left(\left(\mathrm{X}_{\mathrm{nS}}-\dagger\right)^{2} / \Sigma \mathrm{x}^{2}\right)\right]
$$

where $\Sigma x^{2}$ is the corrected sum of squares for $X,(X-\dagger)^{2}$ is the squared difference of the $X_{n s}$ value for the new species from the average $X$ value, and $n$ is the regression sample size.

If the new datum (i.e. BMR of the numbat or aardwolf) were to lie outside these $95 \%$ prediction limits, then it would be significantly different to expected at the 0.05 significance level. If it were to fall within these limits, then the datum would conform to the existing relationship. A one-tail test can be employed if a directional hypothesis is being addressed; we used a 1-tail test in this case as the observed BMR is predicted to be lower than the expected BMR (McNab 1984, 2000). 
The prediction confidence limits are considerably broader than, and should not be confused with, the confidence limits for the regression line (which indicate the range within which the regression line falls at the desired probability level). The standard error $\left(\mathrm{s}_{\mathrm{b}}\right)$ of the slope (b) are calculated (see Zar 1999) as

$$
\mathrm{s}_{\mathrm{b}}=\mathrm{S}_{\mathrm{Y} . \mathrm{X}} \sqrt{ }\left[1 / \Sigma \mathrm{x}^{2}\right]
$$

and the confidence limits of the slope as

$$
\mathrm{b} \pm \mathrm{t}_{\alpha(2),(\mathrm{n}-2)} \mathrm{s}_{\mathrm{b}}
$$

\section{Results}

The highly significant allometric regression equation for 18 species of dasyurid (excluding the numbat) was $\log B M R=0.736 \log M+0.387\left(R^{2}=0.988, F_{1,17}=1418, p\right.$ $<0.001)$. The numbat's BMR of $215.3 \mathrm{ml} \mathrm{O}_{2} \mathrm{~h}^{-1}$ was $83.6 \%$ of expected from mass, but fell inside the $95 \%$ prediction limits for a further datum (Figure 1A). The numbat would have had to have a BMR $<67.8 \%$ of predicted to fall outside the $95 \%$ prediction limits. Even for a one-tail test, the observed BMR of the numbat is within the prediction limit (BMR would have to be $<72.5 \%$ of predicted to differ significantly). The highly significant allometric linear relationship between mass and BMR remained after correction for phylogenetic history (slope $=0.754, \mathrm{R}^{2}=0.945, \mathrm{~F}_{1,16}=277, \mathrm{p}<0.001$ ). Clearly phylogenetic correction did not improve the regression relationship and therefore did not tighten the $95 \%$ prediction limits. Thus the numbat still remained within the $95 \%$ prediction limits (both 1 and 2-tail tests) for the regression after phylogenetic correction (Figure 1B). 
There was a highly significant allometric relationship for 30 species of Carnivora, described by the relationship $\log \operatorname{BMR}\left(\mathrm{ml} \mathrm{O}_{2} \mathrm{~h}^{-1}\right)=0.724$ Mass $(\mathrm{g})+0.675\left(\mathrm{R}^{2}=0.941\right.$, $\left.\mathrm{F}_{1,15}=239, \mathrm{p}<0.001\right)$. The aardwolf had a BMR $\left(2019 \mathrm{ml} \mathrm{O}_{2} \mathrm{~h}^{-1}\right)$ that was only $74.2 \%$ of predicted from the allometric equation, but it fell well within the $95 \%$ prediction limits (Figure 2A). The aardwolf has to have a BMR $<35.4 \%$ (2-tail test) or 41.8\% (1-tail test) of predicted to vary significantly from the allometric regression. After phylogenetic correction, the highly significant allometric regression for the order Carnivora remained (slope $\left.=0.94, \mathrm{R}^{2}=0.897, \mathrm{~F}_{1,29}=253.6, \mathrm{P}<0.001\right)$. Clearly phylogenetic correction did not improve the regression relationship and therefore did not tighten the $95 \%$ prediction limits. Therefore aardwolf remained well within the $95 \%$ prediction limits (1 and 2-tailed tests) after phylogenetic correction (Figure 2B).

\section{Discussion}

The BMR of both the numbat and the aardwolf was considerably lower than predicted from allometric equations for the carnivorous groups from which they diverged $(83.6 \%$ and $74.2 \%$ of expected respectively). This would be considered sufficient to consider that these species had a lower-than-expected BMR using the subjective methodology of many recent studies (see Introduction) for which a range of $43-90 \%$ or $108-179 \%$ of predicted was considered lower-than-predicted or higher-than predicted respectively. The BMRs of numbats and aardwolves would then both be interpreted as support for the hypothesis that termite-eating mammals have a low BMR, presumably reflecting an energetic constraint of their termite diet. In fact, this is the general conclusion drawn by McNab (1984) and for aardwolves by Anderson et al. (1997). Both studies simply used a percent deviation 
from the expected BMR calculated from the regression equation to decide that numbats (52.6\% of predicted for a placental mammal; McNab 1984) and aardwolves (58.0-67.1\% of predicted; Anderson et al. 1997) were lower-than-expected. However it is clear that if their BMR data are analysed with a formal statistical analysis, and each datum compared to the $95 \%$ prediction limits for the appropriate regression, then interpretation of the results is different. Statistically, both numbats and aardwolves have a BMR not significantly lower than we would expect for an equivalently-sized dasyurid marsupial or carnivore respectively (both before and after correction for phylogeny), therefore we conclude that for these species, a termitivourous diet does not result in a reduced BMR.

Why is it such common practise to neglect formal statistical analysis for evaluating new species data? Subjectively comparing a value for an additional species to the value generated from an already-available allometric equation (e.g. Kleiber's line for mammals) is quick and easy. Even when the regression line needs to be calculated in a study, it is still simple to just calculate the $\%$ difference of the new datum from the regression prediction and make a subjective evaluation. In contrast, the calculation of 95\% prediction limits is not widely available in statistical programs, although it is widely described in the biostatistical arena (e.g. Montgomery and Peck, 1982; Myers, 1986; Neter et al., 1990; Draper and Smith, 1998; Zar 1999). Although the hand calculation of prediction limits (see equations 1 and 2) is relatively straightforward, even this might be a deterrent to its use.

Clearly from our analysis of numbat and aardwolf BMR, finding a statistically significant difference for an additional species can be problematic, even for relatively "tight" regression relationships. The regressions for both the dasyurids and carnivores 
were highly significant, with $\mathrm{R}^{2} \mathrm{~s}$ of 0.945 (non-phylogenetically corrected) to 0.988 (phylogenetically corrected) and 0.940 (non-phylogenetically corrected) to 0.941 (phylogenetically corrected) respectively, resulting in relatively narrow prediction limits. The more variability there is in the data set, the wider the $95 \%$ prediction limits will be, and the more difficult it will be to detect significant differences. Some of the variation in the regression relating mass and BMR for mammals (and other animals) presumably results from a non-random selection of mammals for BMR measurement. "Interesting" species with an a priori expectation of being "low" or "high" are often studied by comparative physiologists in an attempt to examine adaptations to particular environmental or life history parameters. This is likely to increase the variation in the regression, widening the prediction limits and increasing the difficulty in obtaining significant differences for single species comparisons.

The position of the species in question along the $\mathrm{X}$ axis also determines how different it must be from expected to differ significantly. The $95 \%$ prediction limits (like the $95 \%$ regression confidence limits) widen as you move away from the mean $\mathrm{X}$ value. Numbats (552 g) were close to the mean mass for the Dasyuroidea (611g) but still would need to be $<72.5 \%$ (1-tail test) of predicted to differ significantly from the Dasyuroidea allometric regression. The aardwolf (7950g) was further from the mean Carnivora body mass $(13280 \mathrm{~g})$ so it is even more difficult to demonstrate significant difference from expected for this species. Aardwolves would have to have a BMR of $<41.8 \%$ (1-tail test) of expected for an equivalently-sized carnivore. 
We have presented here a statistical approach for evaluating whether an additional species differs significantly from a regression line derived for other species. From the 95\% prediction limits neither the numbat nor the aardwolf has a significantly lower-thanpredicted BMR, despite their termitivorous diet. We conclude that it is difficult to statistically show that a single species differs significantly from an allometric relationship. Nevertheless it is essential that single species differences from prediction are assessed by formal statistical analysis. 


\section{References}

Abensperg-Traun MA, Dickman CR, DeBoer ES (1991) Patch use and prey defence in a mammalian myrmecophage the echidna Tachyglossus aculeatus (Monotremata Tachygossidae): A test of foraging efficiency in captive and free-ranging animals. $\mathbf{J}$ Zoology 225:481-494.

Anderson MD, Richardson PRK, Woodall PF (1992) Functional analysis of the feeding apparatus and digestive tract anatomy of the aardwolf Proteles cristatus. J Zool 228:423-434.

Anderson MD, Williams JB, Richardson PRK (1997) Laboratory metabolism and evaporative water loss of the aardwolf, Proteles cristatus. Physiol Zool 70:464469

Archer M (1984) The Australian marsupial radiation. In: Vertebrate Zoogeography and Evolution in Australasia (Animals in Space and Time) (Eds. Archer M. and Clayton G.). Hesperian Press, Carlisle 633-808.

Archer M, Kirsch JAW (1977) The case for the Thylacomyidae and Myrmecobiidae, Gill, 1972, or why are marsupial families so extended? Proc Linn Soc NSW 102:18-25.

Aschoff J, Pohl H (1970) Rhythmic variations in energy metabolism. Fed Proc 29:15411552

Aschoff J (1981) Thermal conductance in mammals and birds: Its dependence on body size and circadian phase. Comp Biochem Physiol 69A:611-619.

Avner A, Kam M, Shkolnik A, Degen AA (2001) Heat production and body temperature of Arabian babblers (Turdoides squamiceps): a bird from hot desert habitats. J Arid Environ 48:59-67 
Baudinette RV, Churchill SK, Christian KA, Nelson JE, Hudson PJ (2000) Energy, water balance and the roost microenvironment in three Australia cave-dwelling bats (Microchiroptera). J Comp Phys 170:439-446

Baverstock PR, Krig M, Birrell J (1990) Evolutionary relationships of Australian marsupials as assessed by albumin immunology. Aust J Zool 37:273-288.

Bininda-Emonds ORP, Gittleman, JL, Purvis A (1999) Building large trees by combining phylogenetic information: a complete phylogeny of the extant Carnivora (Mammalia). Biol Rev 74:143-175

Bonaccorso FJ, McNab BK (2003) Standard energetics of leaf-nosed bats (Hipposieridae): its relationship to intermittent- and protracted-foraging tactics in bats and birds. J Comp Physiol B 173:43-53

Bozinovic F, Ruiz G, Rosenmann M (2004) Energetics and torpor of a South American "living fossil", the microbiotheriid Dromiciops gliroides. J Comp Phys B $174: 293-297$

Bradley SR, Deavers DR (1980) A re-examination of the relationship between thermal conductance and body weight in mammals. Comp Biochem Physiol 65A:465-476.

Burton CT, Weathers WW (2003) Energetics and thermoregulation of the Gouldian finch (Erythrura gouldiae). Emu 103:1-10

Cheverud JM, Dow MM (1985) An autocorrelation analysis of genetic variation due to lineal fission in social groups of Rhesus macaques. Am J Physiol Anthrop 67:113121.

Cooper CE, Withers PC (2002) Metabolic physiology of the numbat (Myrmecobius fasciatus). J Comp Physiol B 172:669-675 
Cooper CE, Withers PC (2003) Field metabolic rate and water turnover of the numbat (Myrmecobius facsiatus). J Comp Physiol B 173:687-693

Cortes A, Tirado C, Rosenmann M. (2003) Energy metabolism and thermoregulation in Chinchilla revicaudata. J Thermal Biol 28: 89-495

Crawford EC, Lasiewski RC (1968) Oxygen consumption and respiratory evaporation in the emu and rhea. Condor 70:333-339.

Draper NR, Smith H (1998). Applied Regression Analysis. John Wiley \& Sons, New York

Geiser F, Brigham RM (2000) Torpor, thermal biology and energetics in Australian longeared bats (Nyctophilus) J Comp Physiol B. 170:153-162

Hayssen V, Lacy RC (1985) Basal metabolic rates in mammals: Taxonomic differences in the allometry of BMR and body mass. Comp Biochem Physiol A 81:741-754

Hinds DS, MacMillen RE (1985) Scaling of energy metabolism and evaporative water loss in heteromyid rodents. Physiol Zool 58:282-298

Hinds DS, MacMillen RE (1986) Scaling of evaporative water loss in marsupials. Physiol Zool 59:1-9

Kalin N, Martin RD, Genoud M (2003) Basal rate of metabolism and temperature eregulation in Goeldi's monkey (Callimico goeldii) Comp Biochem Physiol A $135: 279-290$

Kirsch JAW (1968) Prodromus of the comparative serology of Marsupialia. Nature 217:418-420

Kirsch JAW, Lapointe FJ, Springer MS (1997) DNA-hybridisation studies of marsupials and their implications for metatherian classification. Aust J Zool 45:211-280 
Kirsch JAW, RE Palma (1995) DNA/DNA hybridisation studies of carnivorous marsupials. V. A further estimate of relationships among opossums (Marsupialia: Didelphidae). Mammalia 59:403-425.

Klaassen M, Agrell J, Lindstrom A (2002) Metabolic rate and thermal conductance of lemmings from high-arctic Canada and Siberia. J Comp Physiol B 172:371-378

Kleiber M. (1932) Body size and animal metabolism. Hilgardia 6:315-353.

Lindstrom A, Klaassen M (2002) High basal metabolic rates of shorebirds while in the arctic: A circumpolar view. Condor 105:420-427

Lovegrove BG (2000) The zoogeography of mammalian basal metabolic rate. Am Nat $156: 201-219$

Lovegrove BG, Smith GA (2003) Is 'nocturnal hypothermia' a valid physiological concept in small birds? A study on Bronze Mannikins Spermestes cucullatus. Ibis $145: 547-557$

Mathias ML, Nunes AC, Marques CC, Sousa I, Ramalhinho MG, Aufray JC, Catalan J and Britton-Davidian J (2004) Adaptive energetics in house mice, Mus musculus domesticus, from the island of Porto Santo (Madeira archipelago, North Atlantic). Comp Biochem Physiol A 137:703-709

McNab BK (1984) Physiological convergence amongst ant-eating and termite-eating mammals. J Zoology 203:485-510.

McNab BK (1988) Complications inherent in scaling basal rate of metabolism in mammals. Quat Rev Biol 63:25-54

McNab BK (2000) The standard energetics of mammalian carnivores: Felidae and Hyaenidae. Can J Zool 78:2227-2239 
McNab BK, Bonaccorso FJ (2001) The metabolism of New Guinean pteropidid bats. J Comp Physiol B 171:201-214

McKechnie AE, Lovegrove BG (2003) Faculative hypothermic responses in an Afrotripical arid-zone passerine, the red-headed finch (Amadina erythrocephala). J Comp Physiol B 173:339-346

Merola-Zwartjues M, Ligon JD (2000) Ecological energetics of the Puerto Rican tody: Heterothermy, torpor and intra-island variation. Ecology 81:990-1003

Montgomery DC, Peck EA. (1982). Introduction to Linear Analysis. John Wiley \& Sons, New York

Myers RH (1986) Classical and Modern Regression with Applications. Duxbury Press, Boston.

Nagy KA (1987) Field metabolic rate and food requirement scaling in mammals and birds Ecol Mono 57:111-128

Nagy KA (1994) Field bioenergetics of mammals: What determines field metabolic rates? Aust J Zool 42:43-53

Neter J, W Wasserman, MH Kutner (1990) Applied Linear Statistical Models: Regression, Analysis of Variance, and Experimental Design. Irwin, Boston

Peinke DM, Brown CR (2003) Metabolism and thermoregulation in the springhare (Pedetes capensis). J Comp Physiol B 173:347-353

Redford KH, JG Dorea (1984) The nutritional value of invertebrates with emphasis on ants and termites as food for mammals. J Zool 203:385-395

Reynolds PS, Lee RM (1996) Phylogenetic analysis of avian energetics: Passerines and nonpasserines do not differ. Am Nat 147:735-759 
Song Z, Wang D (2003) Metabolism and thermoregulate in the striped hamster Cricetulus barabensis. J Thermal Biol 28:509-514

Schleucher E, Withers PC (2001) Re-evaluation of the allometry of wet thermal conductance for birds. Comp Biochem Physiol A 129:821-827

Schleucher E (2002) Metabolism, body temperature and thermal conductance of fruitdoves (Aves: Columbidae, Treroninae) Comp Biochem Physiol A 131:417-428

Weathers WW, Gerhart KL, Hodum PJ (2000) Thermoregulation in Antarctic fulmarine petrels. J Comp Physiol B 170:561-572

White CR, Seymour RS (2003) Mammalian basal metabolic rate is proportional to body mass. Proc Nat Ac Sci 100:4046-4049

Williams JB (1996) A phylogenetic perspective of evaporative water loss in birds. Auk $113: 457-472$.

Williams JB (2001) Energy expenditure and water flux of free-living Dune Larks in the Namib: a test of the reallocation hypothesis on a desert bird. Func Ecol 15:175185

Williams TM, Haun J, Davis RW, Fuiman LA, Kohin S (2001) A killer appetite: metabolic consequences of carnivory in marine mammals. Comp Biochem Physiol A 129:785-796

Williams JB, Munoz-Garcia A, Ostrowski S, Tieleman BI (2004) A phylogenetic analysis of basal metabolism, total evaporative water loss, and life-history among foxes from desert and mesic regions. J Comp Physiol B 174:29-39

Withers PC, Cooper CE, Larcombe AN (in press) Environmental correlates of physiological variables in marsupials. Physiol Biochem Zool in press 
Withers PC, Thompson GG, Seymour RS (2000) Metabolic physiology of the northwestern marsupial mole, Notoryctes caurinus (Marsupialia: Notorycidae). Aust J Zool 48:241-258.

Zar JH (1999) Biostatistical Analysis. Prentice-Hall, Englewood Cliffs, New Jersey 


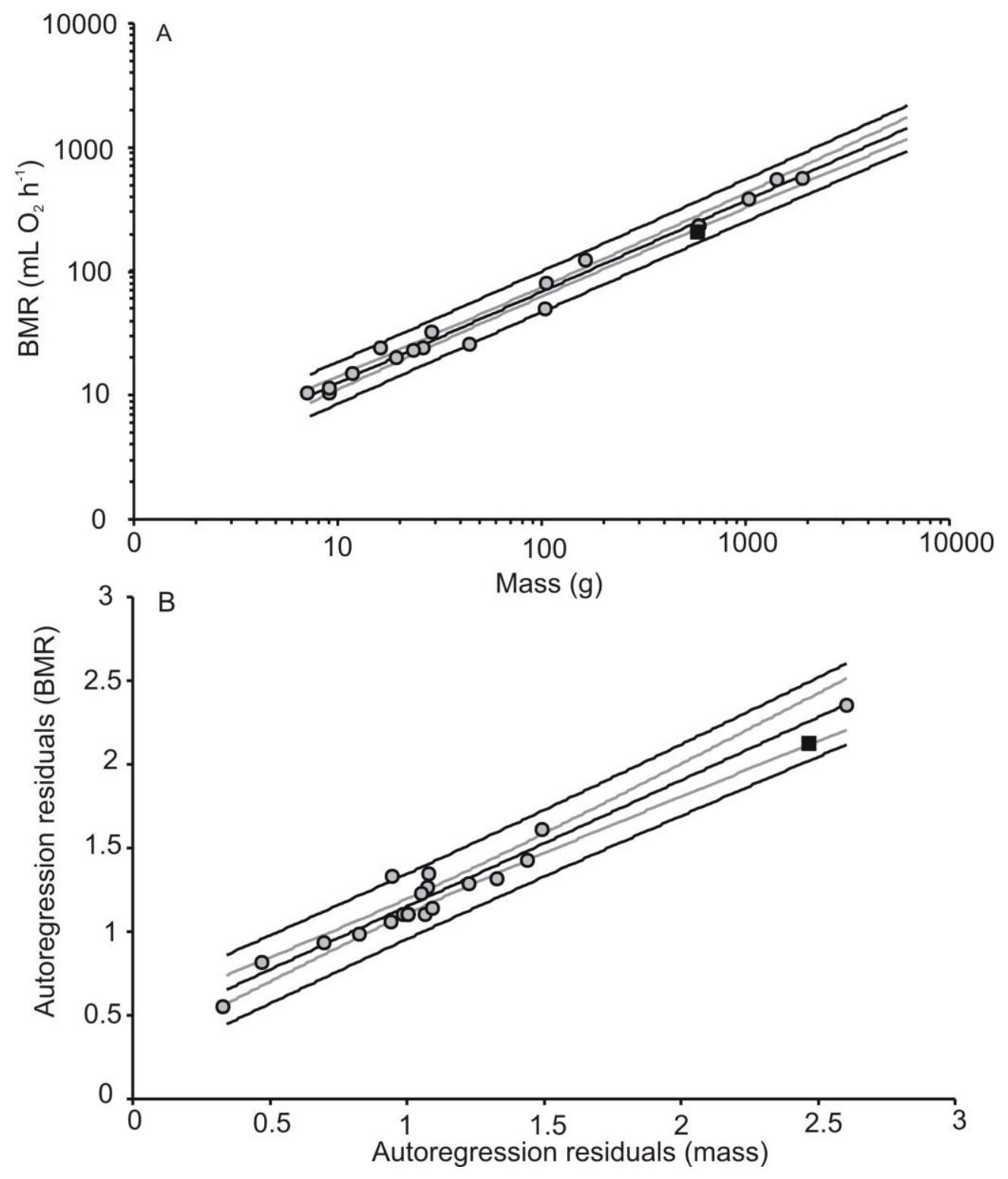

Figure 1: The relationship between mass (g) and basal metabolic rate (BMR; $\mathrm{mL} \mathrm{O}_{2} \mathrm{~h}^{-1}$ ) for 18 species from the superfamily Dasyuroidea (grey circles) before (A) and after (B) phylogenetic correction. The numbat is indicated by a dark square, the regression line and 95\% prediction limits for predicting a further datum by dark lines, and the regression 95\% confidence limits by light grey lines. 

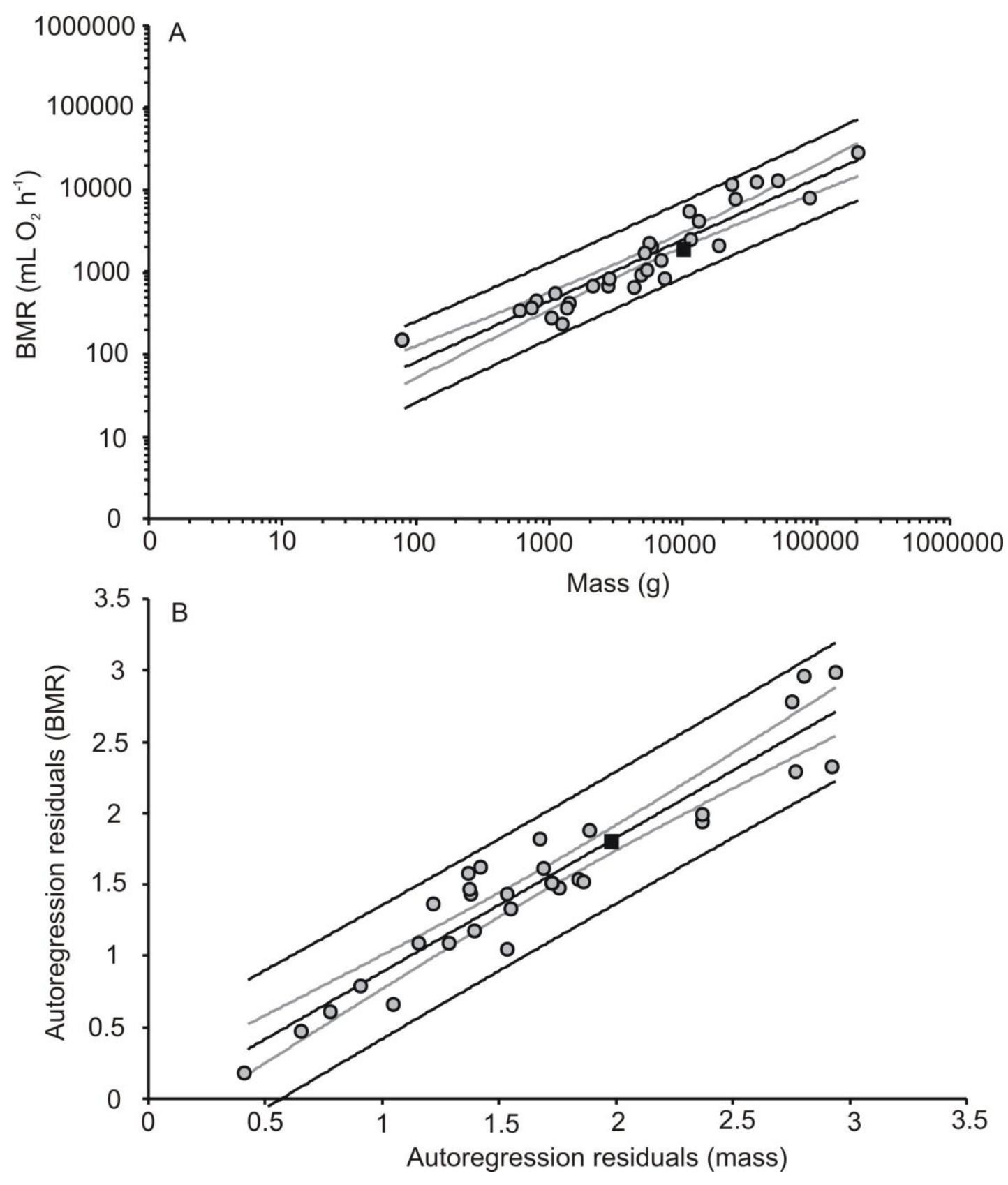

Figure 2: The relationship between mass ( $\mathrm{g}$ ) and basal metabolic rate (BMR; $\mathrm{mL} \mathrm{O}_{2} \mathrm{~h}^{-1}$ ) for 30 species from the order Carnivora (grey circles) before (A) and after (B) phylogenetic correction. The aardwolf is indicated by a dark square, the regression line and $95 \%$ prediction limits for predicting a further datum by dark lines, and the regression 95\% confidence limits by light grey lines. 